\title{
The hematopathologist as detective
}

\author{
Barbara J. Bain
}

Received: 16 May 2011 / Accepted: 16 May 2011 /Published online: 25 May 2011

(C) Springer-Verlag 2011

\begin{abstract}
The skills required of a physician are akin to those of a detective, fictional or real. The diagnostic process is based on observation, deduction, and inference. We may thus see the hematopathologist as using the same skills as a detective. Sometimes, the hematopathologist is involved, usually inadvertently, in the detection of actual crime or other illicit activity. More often, the skills of a detective are being applied in the normal diagnostic process.
\end{abstract}

Keywords Hematopathology · Hematopathologist .

Detection $\cdot$ Detective $\cdot$ Diagnosis $\cdot$ Diagnostic process

The skills required of a physician are akin to those needed for detecting. Sir Arthur Ignatius Conan Doyle (1859-1930), the creator of perhaps the most famous British detective, was a Scottish physician. He modeled his great creation on his own mentor, the surgeon Joseph Bell, whom he served as an outpatient clerk in the Edinburgh Royal Infirmary. Dr. Joseph Bell (1837-1911), like Sherlock Holmes, was noted for drawing large conclusions from small observations and for deducing a great deal about a man before he had even spoken. Conan Doyle wrote in a letter to Bell, "It is most certainly to you that I owe Sherlock Holmes. Though in the stories I have the advantage of being able to place him in all sorts of Dr.matic positions, I do not think that his analytical work is in the least an exaggeration of some effects which I have seen you produce in the outpatient ward. Round the centre of deduction and inference and observation which I have heard you inculcate I have tried to build up a man who pushed the thing as far as it

\section{B. J. Bain $(\bowtie)$}

Department of Haematology, St Mary's Hospital Campus of Imperial College Faculty of Medicine, St Mary's Hospital, Praed Street,

London W2 1NY, UK

e-mail: b.bain@ic.ac.uk would go, further occasionally." [1]. Conan Doyle was also influenced in his creation of Holmes by Sir Henry Littlejohn, who taught him forensic medicine, and by Sir Robert Christison, professor of medical jurisprudence and an expert in poisons, who was involved in the Burke and Hare trial.

The hematopathologist is one step further away from the patient than other practicing physicians. Unlike Dr. Joseph Bell or Conan Doyle's fictional creation, he cannot recognize an accent, deduce a man's occupation from his hands, recognize a sailor from his rolling gait, or tell where a sailor has been from the tattoos he carries. Do the skills of the detective have a role in hematopathology? We may well consider that they do, since observation, deduction, and inference are key features of pathological diagnosis. However the hematopathologist is at a disadvantage in comparison with the detective, fictional or otherwise, since he is dependent on others to provide him with some of the key information that must supplement his own observations. The critical background information that is sometimes lacking to the hematopathologist includes the ethnic origin, travel history and history of exposure to drugs, growth factors, and toxic substances. Without these clues, diagnoses may be missed. A diagnosis of adult $\mathrm{T}$ cell leukemia/lymphoma may not be considered when it is not realized that a patient with a $\mathrm{T}$ cell lymphoma is AfroCaribbean. A lack of awareness of a history of travel to an endemic area can contribute to misdiagnosis of leishmaniasis as lymphoma [2], hemophagocytic lymphohistiocytosis [3], or dyserythropoietic anemia [4].

\section{The hematopathologist in a forensic setting}

Sometimes the hematopathologist observes pathological features resulting from a crime, such as dyshemopoiesis 
due to arsenic poisoning, or bone marrow hypoplasia as a result of the administration of busulfan with homicidal intent. A hematology laboratory in the USA detected excess heparin in the blood of a baby on two occasions, the heparin having been administered by a homicidal nurse; sadly 16 babies were murdered before the culprit was identified and charged (Association for Clinical Pathology News Brief 2007).

Study of blood groups can contribute to paternity investigations and the identification of the source of blood stains.

Other illicit activities that may be suspected or detected in the hematology laboratory include non-therapeutic use of erythropoietin (suspected when the red cell count, hemoglobin concentration, and hematocrit of a sportsman are unexpectedly high) and blood doping (when an individual not only has a high hematocrit but is also found to have red blood cells of more that one group, using either traditional agglutination techniques or flow cytometry). A coagulation abnormality due to self-administration of warfarin is occasionally recognized and should be particularly suspected in those with occupational availability of the drug or a history of previous anticoagulant therapy. Ingestion of "superwarfarins," vitamin K-antagonizing rodenticides, leads to a similar but prolonged state of coagulation, which can be suspected because of refractoriness to vitamin $\mathrm{K}$ [5].

\section{Something unexpectedly detected}

"The world is full of obvious things which nobody by any chance ever observes."

The Hound of the Baskervilles, Sir Arthur Conan Doyle

Fortunately the detection of criminal or other illicit activity by a hematopathologist is rare. Much more frequently, something unexpected is detected, but the cause is less sinister. Hematological abnormalities may lead to the detection of inadvertent exposure to heavy metals: (i) lead poisoning should be suspected when there is a hypochromic microcytic anemia with an increased reticulocyte count and basophilic stippling; (ii) arsenic exposure can lead to dyserythropoiesis and thrombocytopenia; (ii) copper deficiency causes anemia, neutropenia, vacuolation of hemopoietic precursors, ring sideroblasts, and hemosiderincontaining plasma cells. Detection of these abnormalities requires consideration also of the blood count and film and the bone marrow aspirate since most of the relevant abnormalities are not apparent in a trephine biopsy section. A relevant clinical history and physical examination may also be indispensible in raising the suspicion. Lead poisoning has resulted from Indian and Burmese cosmetics, glazes of ceramic containers, and traditional remedies such as Daw Tway, a digestive remedy associated with lead poisoning in Burma. Arsenic poisoning has resulted from intake of alternative medications [6] including Ayurvedic medicines [7]. Copper deficiency should be suspected when there has been excess intake of oral zinc or following gastric bypass surgery; knowledge that the patient has a peripheral neuropathy may be a clue to the diagnosis.

The hematologist may suspect accidental or deliberate exposure to an oxidant chemical when blood samples are unusually dark as a result of methemoglobinemia.

An accidental heparin overdose may be suspected from coagulation tests; in a US hospital, it was a laboratory technician who helped determine that the heparin flush dose used in a pediatric special care baby unit was 1,000 times the required dose after three babies had already died of hemorrhage; two other babies were consequently spared (Association for Clinical Pathology News Brief 2007).

\section{New discoveries as the result of detective activity}

"Breadth of view...is one of the essentials of our profession. The interplay of ideas and the oblique uses of knowledge are often of extraordinary interest."

The Valley of Fear, Sir Arthur Conan Doyle

Important new discoveries can result from the detective activities of hematopathologists. The suspicion of the viral origin of Burkitt lymphoma was a classic piece of detection; admittedly this was by a surgeon, but pathologists contributed to its recognition. In 1957 Denis Burkitt, working in Uganda, saw two children with tumors of the jaw, initially interpreted as sarcoma $[8,9]$. Subsequently the lesions were identified as lymphoma by Drs. C. T. O'Conor and J. N. P. Davies in the Department of Pathology in Kampala, and later Dennis Wright showed that this tumor could be distinguished from other lymphomas [10]. Burkitt had never seen anything similar and thought it could be a new entity. He initiated epidemiological studies, printing leaflets with photographs and distributing them all over Africa. He asked if anything similar had been seen, and by means of a map on his wall and some pins, he recognized the lymphoma belt. He lectured on the subject at the Middlesex Hospital in 1961, and Michael Anthony (Tony) Epstein was in the audience. The two men suspected an arthropod-borne oncogenic virus. Burkitt's postal survey was followed by a 10,000 -mile safari, visiting 60 hospitals in 10 African countries. The new lymphoma was found to be related to latitude, altitude, and rainfall [11]. Subsequently the feat of detection was completed when Epstein and colleagues identified a virus in cultured lymphoma cells [12], and Henle and Henle [13] found that it was a previously unrecognized herpesvirus, which they named the 
Epstein-Barr virus after Epstein and his co-worker Dorothy Barr.

The suspicion that adult $\mathrm{T}$ cell leukemia/lymphoma (ATLL) could be explained on the basis of an oncogenic virus with a peculiar geographic distribution was a similarly astute piece of deduction. When this lymphoma was first recognized in Japan, it was discovered that although the patients resided in three of the four major islands that comprise Japan, particularly in and near Tokyo, they had all been born on the southwestern island of Kyushu, particularly in the Kagoshima prefecture [14]. The hypothesis based on the data was subsequently shown to be correct. In 1979 Gallo and colleagues discovered the first known human retrovirus, now designated human $\mathrm{T}$ cell lymphotropic virus $\mathrm{I}$, in a patient with a cutaneous lymphoma that was not initially recognized as being the same as the Japanese condition [15]. A year later, they demonstrated that Japanese patients with ATLL had antibodies to the same virus [16]. Subsequently Catovsky and colleagues recognized a lymphoma in Afro-Caribbeans in the UK that was indistinguishable from the Japanese condition and confirmed that antibodies to the same virus were present in UK patients [17]. Another geographic cluster had been recognized.

\section{Detection in daily practice}

"It is an old maxim of mine that when you have excluded the impossible, whatever remains, however improbable, must be the truth."

The Adventure of the Beryl Coronet, Sir Arthur Conan Doyle

The hematopathologist practices detection as a routine. Sometimes he practices Conan Doyle's methodology of "deduction and inference and observation." On other occasions, the techniques are more akin to those of the fictional detectives created by Agatha Christie, with all the suspects being lined up and eliminated one by one. However, here again, Sherlock Holmes got there first.

Before arriving at a diagnosis, there may be puzzling features of the biopsy specimen to be dealt with. The trephine biopsy may be taken as an example. The hematopathologist must recognize artifacts that can cause confusion including crushing, squeezing, and twisting, the latter sometimes simulating fibrosis. Extraneous tissues, including neoplastic and dysplastic tissues, that have attached themselves to the biopsy specimen must be recognized; if their nature is not certain, hematopathologists have sometimes even resorted to HLA typing of the unexplained tissue that has been dug out of the block to confirm that it is extraneous. Tissues that have been driven into the biopsy specimen during the diagnostic procedure can be particularly confusing. They can include epidermis, fat, striated muscles, cartilage, sweat glands, sebaceous glands, hair follicles, synovium, neural tissue, and even part of a gouty tophus [18]. Some of these tissues are readily recognized, but others can simulate tumor infiltration.

Detection involves looking at tissues other than the one of immediate interest-inspecting the scene of the crime. Again taking the trephine biopsy specimen as an example, inspection of the bones may reveal that bone marrow fibrosis is not due to primary myelofibrosis or another hematological neoplasm but is the result of Paget's disease, primary hyperparathyroidism, or renal osteodystrophy.

Detection includes making the invisible visible by means of immunohistochemistry. This may reveal a subtle infiltrate that cannot be identified with certainty on standard stains. Such subtle infiltrates include intrasinusoidal and interstitial lymphomatous infiltrates, some plasma cell infiltrates, some carcinomatous infiltrates, and a subtle increase of blast cells. Immunohistochemistry can also be very valuable in demonstrating the nature of distorted cells, such as carcinoma cells or dysplastic megakaryocytes, embedded in fibrous tissue.

The detection process can be further enhanced by the application of fluorescence in situ hybridization or molecular analysis to the biopsy specimen. A diagnosis of systemic mastocytosis, for example, may be confirmed by a mast cell tryptase stain to confirm the lineage involved, immunohistochemistry to show aberrant expression of CD2 and CD25, and molecular analysis, if necessary on a microdissected specimen, to demonstrate a KIT mutation.

The days when diagnosis rested just on a hematoxylin and eosin-stained specimen are past. The hematopathologist must now use all necessary modalities to reach a diagnosis. All the data necessary must be assembled and used, always being interpreted in a clinical context.

"The temptation to form premature theories upon insufficient data is the bane of our profession."

The Valley of Fear, Sir Arthur Conan Doyle

Hematopathology must be practiced with humility, seeking always to discover the truth. The hematopathologist must be careful never to settle prematurely on a diagnosis, closing his mind to other possibilities.

"It is a capital mistake to theorize before you have all the evidence. It biases the judgment."

A Study in Scarlet, Arthur Conan Doyle

\section{Conclusions}

The diagnostic process pursued by the hematopathologist has much in common with the process of detection. Both 
are based on meticulous observation, deduction and inference, and ultimately proof. Fictional and real detectives share characteristics with the hematopathologist.

Acknowledgements Helpful discussions with Dr. David Clark and Dr. Bridget Wilkins are acknowledged.

Conflict of interest The author declares that she has no conflict of interest.

\section{References}

1. Davidson G (2006) Detecting signs in Holmes from homes. The Scotsman, 29 June 2006

2. Kawakami A, Fukunaga T, Usui M, Asaoka H, Noda M, Nakajima T, Hashimoto Y, Tanaka A, Kishi Y, Numano F (1996) Visceral leishmaniasis misdiagnosed as malignant lymphoma. Intern Med 35:502-506

3. Gagnaire MH, Galambrun C, Stéphan JL (2000) Hemophagocytic syndrome: a misleading complication of visceral leishmaniasis in children - a series of 12 cases. Pediatrics 106:e58

4. Olivieri O, Gandini G, Baiocco R, Aprili G, Falezza G, De Sandre $\mathrm{G}$ (1987) Visceral leishmaniasis presenting as dyserythropoiesis associated with increased i-antigenicity of erythrocytes. Haematologica 72:163-165

5. Chow EY, Haley LP, Vickars LM, Murphy MJ (1992) A case of bromadiolone (superwarfarin) ingestion. CMAJ 147:60-62

6. Pye KG, Kelsey SM, House IM, Newland AC (1992) Severe dyserythropoiesis and autoimmune thrombocytopenia associated with ingestion of kelp supplements. Lancet 339:1540
7. Khandpur S, Malhotra AK, Bhatia V, Gupta S, Sharma VK, Mishra R, Arora NK (2008) Chronic arsenic toxicity from Ayurvedic medicines. Int J Dermatol 47:618-621

8. Burkitt D (1958) A sarcoma involving the jaws in African children. Br J Surg 46:218-223

9. Burkitt DP (1983) The discovery of Burkitt's lymphoma. Cancer 51:1777-1786

10. Wright DH (1970) Microscopic features, histochemistry, histogenesis and diagnosis. In: Burkitt DP, Wright DH (eds) Burkitt's lymphoma. Livingstone, Edinburgh, pp 82-102

11. Burkitt D (1962) Distribution of Burkitt's lymphoma (association with areas of low elevation). Nature 194:232-234

12. Epstein MA, Achong BG, Barr YM (1964) Virus particles in cultured lymphoblasts from Burkitt's lymphoma. Lancet 1:702703

13. Henle W, Henle G, Lennette ET (1979) The Epstein-Barr virus. Sci Am 241:48-59

14. Uchiyama T, Yodoi J, Sagawa K, Takatsuki K, Uchino H (1977) Adult T-cell leukemia: clinical and hematologic features of 16 cases. Blood 50:481-492

15. Poiesz BJ, Ruscetti FW, Gazdar AF, Bunn PA, Minna JD, Gallo RC (1980) Detection and isolation of type C retrovirus particles from fresh and cultured lymphocytes of a patient with cutaneous T-cell lymphoma. Proc Natl Acad Sci USA 77:7415-7419

16. Gallo RC (1981) Kyoto Workshop on some specific recent advances in human tumor virology. Cancer Res 41:4738-4739

17. Catovsky D, Greaves MF, Rose M, Galton DA, Goolden AW, McCluskey DR, White JM, Lampert I, Bourikas G, Ireland R, Brownell AI, Bridges JM, Blattner WA, Gallo RC (1982) The human type-C retrovirus, HTLV, in Blacks from the Caribbean region, and relationship to adult T-cell leukemia/lymphoma. Lancet 1:639-643

18. Bain BJ, Clark DM, Wilkins BS (2010) Bone marrow pathology, 4th edn. Wiley-Blackwell, Oxford 